\title{
Heterophyllin B inhibits the adhesion and invasion of ECA-109 human esophageal carcinoma cells by targeting PI3K/AKT/ $\beta$-catenin signaling
}

\author{
JI-CHENG TANTAI $^{1 *}$, YAO ZHANG ${ }^{2 *}$ and HENG ZHAO ${ }^{1}$ \\ ${ }^{1}$ Department of Thoracic Surgery, Shanghai Chest Hospital, Shanghai Jiao Tong University, Shanghai 200030; \\ ${ }^{2}$ Department of Gastroenterology and Hepatology, Renji Hospital, School of Medicine, \\ Shanghai Jiao Tong University, Shanghai 200001, P.R. China
}

Received November 12, 2014; Accepted August 20, 2015

DOI: $10.3892 / \mathrm{mmr} .2015 .4659$

\begin{abstract}
The present study aimed to measure the effect of heterophyllin $\mathrm{B}(\mathrm{HB})$ on the adhesion and invasion of ECA-109 human esophageal carcinoma cells, and examine the possible mechanism involved. A Cell Counting kit 8 assay was performed to determine the cell viability. Cell adhesion and invasion were determined following treatment of the ECA-109 cells with $\mathrm{HB}(0,10,25$ and $50 \mu \mathrm{M})$ for $24 \mathrm{~h}$. The levels of phosphorylated (p-)ATK and p-phosphoinositide 3-kinase $(\mathrm{PI} 3 \mathrm{~K})$, and the protein levels of $\beta$-catenin were measured using western blot analysis. The mRNA and protein expression levels of E-cadherin, vimentin, snail, matrix metalloproteinase (MMP)2 and MMP9 were detected using reverse trancsription-quantitative polymerase chain reaction and western blot analyses, respectively. HB $(10,25$ and $50 \mu \mathrm{M})$ significantly suppressed the adhesion and invasion of the ECA-109 human esophageal carcinoma cells in a dose-dependant manner. The expression levels of $\mathrm{p}$-ATK, $\mathrm{p}$-PI3K and $\beta$-catenin were markedly decreased. The expression of E-cadherin was promoted, whereas the expression levels of snail, vimentin, MMP 2 and MMP 9 were decreased significantly in the ECA-109 cells treated with HB. In addition, HB inhibited the adhesion and invasion induced by PI3K activating peptide in the ECA-109 cells, and the protein expression levels were also adjusted. These results suggested that $\mathrm{HB}$ effectively suppressed the adhesion and invasion of the human esophageal carcinoma cells by mediating the PI3K/AKT/ $\beta$-catenin pathways and regulating the expression levels of adhesion- and invasion-associated genes.
\end{abstract}

Correspondence to: Professor Heng Zhao, Department of Thoracic Surgery, Shanghai Chest Hospital, Shanghai Jiao Tong University, 241 Huaihai Road, Changning, Shanghai 200030, P.R. China E-mail: zhaoheng6511701@163.com

${ }^{*}$ Contributed equally

Key words: heterophyllin B, esophageal carcinoma, adhesion, invasion, phosphoinositide 3-kinase/AKT/ $\beta$-catenin

\section{Introduction}

Esophageal carcinoma is one of the most common types of carcinoma of the digestive system, and its mortality rate is inferior only to gastric carcinoma, ranking the second highest among cancers of the digestive system in China $(1,2)$. Esophageal cancer poses a serious threat to human health, and almost 300,000 individuals succumb to mortality every year worldwide (3). Chemical carcinogens; biological carcinogens, including infections from certain viruses, bacteria or parasites; a lack of trace elements and vitamins; inappropriate dietary habits and genetic inheritance can lead to esophageal carcinoma. The majority of patients diagnosed with esophageal cancer suffer from dyspnea, dysphagia and pain during treatment (4). Currently, chemotherapy, radiotherapy and surgical treatment are the common strategies used for esophageal carcinoma. However, the harmful side effects, high costs and rates of recurrence caused by traditional therapies result in low cure rates. Consequently, it is urgent to investigate novel efficient strategies for the treatment of esophageal carcinoma. The screening serviceable anticancer products from medicinal plants has been an intensive area of investigation in various cancer therapies.

Cyclic lipopeptides exist in abundance in medicinal plants, which exhibit antitumor, anti-inflammatory, antifungal and antibacterial activities (5-7). Heterophyllin B (HB) is one of the active compounds existing in Pseudostellaria heterophylla (Miq.) Pax, and is often used in promoting the production of fluid in Chinese medicine. HB belongs to the cyclic lipopeptides, however, its anticancer activity remains to be elucidated (8).

The present study aimed to investigate the effect of $\mathrm{HB}$ on the proliferation, adhesion and invasion of ECA-109 human esophageal carcinoma cells, and determine the possible mechanisms involved. The results of this investigation aim to provide novel strategies for the treatment of esophageal cancer.

\section{Materials and methods}

Cell line and treatment. The ECA-109 human esophageal carcinoma cell line was purchased from American Type 
Culture Collection (Manassas, VA, USA) and the cells were maintained in Dulbecco's modified Eagle's medium (DMEM; GE Healthcare Life Sciences, Logan, UT, USA), supplemented with $10 \%$ fetal bovine serum (FBS; Gibco Life Technologies, Carlsbad, CA, USA), $1 \%$ penicillin/streptomycin (Solarbio, Beijing, China) at $37^{\circ} \mathrm{C}$ in a $5 \% \mathrm{CO}_{2}$ humidified tissue culture incubator. The 740Y-P phosphoinositide 3-kinase (PI3K) activating peptide was purchased from Tocris Bioscience (Shanghai, China).

Cell Counting Kit-8 (CCK8) assay. The cell proliferation status was assessed using a CCK8 assay (Beyotime Institute of Biotechnology, Haimen, China). Briefly, the ECA-109 cells were seeded in 96-well plates at the density of $2 \times 10^{3}$ cells/well with $100 \mathrm{ml}$ culture medium. Following culture for $24 \mathrm{~h}$, $740 \mathrm{Y}-\mathrm{P}(500 \mu \mathrm{g} / \mathrm{ml})$ and/or HB were added to the medium to final concentrations $(0,5,10,20,50,100$ and $200 \mu \mathrm{M} \mathrm{HB})$. The cells were then cultured for another 12, 24 and $48 \mathrm{~h}$. Subsequently, $20 \mathrm{ml}$ CCK8 solution was added to each well, and the culture was incubated for another $1 \mathrm{~h}$ at $37^{\circ} \mathrm{C}$. The optical density (OD) values were read at $450 \mathrm{~nm}$ using a microplate reader (Thermo Fisher Scientific).

Adhesion assay. Cells in logarithmic phase were digested using $0.25 \%$ trypsin (Gibco Life Technologies) and then suspended in RPMI-1640 medium (GE Healthcare Life Sciences) containing 10\% FBS). The cells were seeded into a 12-plate microplate at a density of $1 \times 10^{5}$ cells $/ \mathrm{ml}$ and then incubated for $1 \mathrm{~h}$ at $37^{\circ} \mathrm{C}$. The supernatant was discarded and the cells were washed twice using phosphate-buffered saline (PBS; Gibco Life Sciences). Subsequently, 4\% paraformaldehyde (JRDun Biotechnology, Co., Ltd., Shanghai, China) was supplemented for $15 \mathrm{~min}$ at room temperature, and cells were stained using Giemsa (JRDun Biotechnology, Co., Ltd.) for $30 \mathrm{~min}$. Then cells were washed with PBS several times and the OD values were read at $570 \mathrm{~nm}$ using a microplate reader (Multiskan MK3; Thermo Fisher Scientific). The adhesion was calculated using the following formula: Adhesion rate $(\%)=\left(\mathrm{OD}_{1} / \mathrm{OD}_{0}\right) \times 100 \%$, where $\mathrm{OD}_{1}$ represents the $\mathrm{HB}$ treated group and $\mathrm{OD}_{0}$ represents the control group.

Cell invasion assay. A cell invasion assay was performed using a 24-well Transwell chamber with a pore size of $8 \mu \mathrm{m}$ (Sigma-Aldrich, St. Louis, MO, USA). The inserts were coated with $50 \mu$ l Matrigel (dilution, 1:2; BD Biosciences, Franklin Lakes, NJ, USA). The cells, previously treated with 740Y-P $(500 \mu \mathrm{g} / \mathrm{ml})$ and/or HB for $24 \mathrm{~h}$, were transferred into the upper

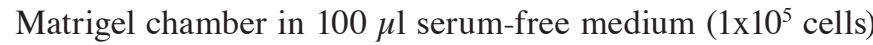
and incubated for $24 \mathrm{~h}$ at $37^{\circ} \mathrm{C}$. The lower chamber was filled with medium containing $10 \%$ FBS as a chemoattractant. Following incubation, the cells, which had passed through the filter were fixed and stained using $0.1 \%$ crystal violet (JRDun Biotechnology, Co., Ltd.). The numbers of invaded cells were counted in five randomly-selected high power fields under a microscope (CX41-72C02; Olympus Corp., Toyko, Japan).

Western blot analysis. Cell lysates were prepared using immunoprecipitation assay buffer (RIPA, Beyotime Institute of Biotechnology) containing $0.01 \%$ protease and phosphatase inhibitor (Sigma-Aldrich). Cells were incubated at $4^{\circ} \mathrm{C}$ for $10 \mathrm{~min}$ followed by $95^{\circ} \mathrm{C}$ for $10 \mathrm{~min}$ and subsequently centrifuged at room temperature at $12,000 \mathrm{x}$ g for $10 \mathrm{~min}$. The protein contained in the supernatant was quantified using a bicinchoninic acid kit (cat no. PICPI23223; Thermo Fisher Scientific). Equal amounts of protein (20-30 $\mu \mathrm{g})$ were separated by $10 \%$ SDS-PAGE (JRDun Biotechnology, Co., Ltd., Shanghai, China) and transferred onto nitrocellulose membranes via the semi-dry blotting method using a three-buffer system. Subsequently, membranes were incubated with antibodies against PI3K (cat no. Ab127617; 1:1,000 dilution), p-PI3K (cat no. Ab86714; 1:1,000 dilution), vimentin (cat no. Ab92547, 1:1,000 dilution), snail (cat no. Ab135708; 1:100 dilution), MMP2 (cat no. Ab110186; 1:500 dilution) or MMP9 (cat no. Ab38898; 1:1,000 dilution) (all from Abcam, Cambridge, MA, USA) as well as antibodies against AKT (cat no. 9272S; 1:1,000 dilution), phosphorylated (p-)AKT (cat no. 4058S; $1: 1,000$ dilution) $\beta$-catenin (cat no. 8480S; $1: 1,000$ dilution), E-cadherin (cat no. 3185; 1:1,000 dilution) and GAPDH (cat no. 5471; 1:1,500 dilution) (all from Cell Signaling Technology, Inc., Danvers, MA, USA). Protein loading was estimated using mouse anti-GAPDH monoclonal antibody (CST, cat. no. 5174, 1:1,000 dilution) as a an internal control. Blots were then incubated for $1 \mathrm{~h}$ at $37^{\circ} \mathrm{C}$ with goat anti-mouse or anti-rabbit secondary antibody (Beyotime Institute of Biotechnology). LabWorks Image Acquisition and Analysis software (UVGL-58; UVP, Upland, CA, USA) were used to quantify band intensities. Antibodies were purchased from Cell Signaling Technology, Inc. (Beverly, MA, USA).

Reverse-transcription quantitative polymerase chain reaction (RT-qPCR). The ECA-109 human esophageal carcinoma cells were seeded at a density of $5 \times 10^{5}$ cells/well into 6 -well plates, cultured overnight and then treated with $\mathrm{HB}(10,25$ and $50 \mu \mathrm{M}$ ) at $37^{\circ} \mathrm{C}$ for $6 \mathrm{~h}$. Total RNA from the HB-treated cells was isolated using TRIzol reagent (Invitrogen Life Technologies). The RT reaction was performed using $2 \mu \mathrm{g}$ total RNA using a First Strand cDNA kit (Sigma-Aldrich), according to the manufacturer's instructions. PCR amplification was performed for $10 \mathrm{~min}$ at $95^{\circ} \mathrm{C}$, followed by 40 cycles at $95^{\circ} \mathrm{C}$ for $15 \mathrm{sec}$ and annealing/extension at $60^{\circ} \mathrm{C}$ for $45 \mathrm{sec}$, in an ABI 7300 Thermocycler (Applied Biosystems, Foster City, CA, USA), using an SYBR Premix Ex Taq kit (Takara Bio, Inc., Otsu, Japan). The specific primer sequences for each gene were as follows: forward 5'-GTTGTTGGGCAT AGAGAC-3' and reverse 5'-CAGGGCAGTTTGAATAGC-3' for E-cadherin (125 bp product); forward 5'-GCGTGAAAT GGAAGAGAAC-3' and reverse 5'-TGGAAGAGGCAGAGA AATC-3' for vimentin (217 bp product); forward 5'-TTCCTG AGCTGGCCTGTCTG-3' and reverse 5'-TGGCCTGAG GGTTCCTTGTG-3' for SNAI (165 bp product); forward 5'-TTGACGGTAAGGACGGACTC-3' and reverse 5'-GGC GTTCCCATACTTCACAC-3' for MMP 2 (134 bp product); forward 5'-AAGGGCGTCGTGGTTCCA ACTC-3' and reverse 5'-AGCATTGCCGTCCTGGGTGTAG-3' for MMP 9 (210 bp product) and forward 5'-CACCCACTCCTCCAC CTTTG-3' and reverse 5'-CCACCACCCTGTTGCTGTAG-3' for GAPDH (110 bp product). Data analysis was performed using the $2^{-\triangle \Delta C T}$ method for relative quantification (9), and all samples were normalized to GAPDH, which was used as an endogenous control $(10,11)$. 
Statistical analysis. GraphPad Prism 5.0 software (GraphPad Software, Inc., La Jolla, CA, USA) was used for statistical analysis. Values are expressed as the mean \pm standard deviation of the mean. The differences between groups were analyzed using Student's $t$-test when only two groups were compared, or using one-way analysis of variance when more than two groups were compared. All tests performed were two-sided. $\mathrm{P}<0.05$ was considered to indicate a statistically significant difference.

\section{Results}

Effect of HB on ECA-109 human esophageal carcinoma cell proliferation. The in vitro effects of HB on ECA-109 cell proliferation were measured using an CCK8 assay (Fig. 1). Compared with the control group, HB significantly decreased ECA-109 cell proliferation in the 75, 100 and $200 \mu \mathrm{M}$ groups $(\mathrm{P}<0.05)$. However, the lower concentrations of $\mathrm{HB}(5,10,25$ and $50 \mu \mathrm{M})$ did not reduce cell viability. No significant differences were observed between the group exposed to $5 \mu \mathrm{M}$ or the group exposed to $50 \mu \mathrm{M}$. Therefore, the doses of 10,25 and $50 \mu \mathrm{M}$ were selected for use in the subsequent adhesion and invasion investigations.

$H B$ inhibits the adhesion and invasion of ECA-109 esophageal carcinoma cells. The adhesion of carcinoma cells to the extracellular matrix and basement membranes is regarded as an initial step in the invasive process of metastatic tumor cells $(12,13)$. In the present study, the effects of different concentrations of HB on human esophageal cancer cell adhesion were determined by the cell adherence, as previously described. As shown in Fig. 2A, exposure to 10, 25 and $50 \mu \mathrm{M}$ HB notably suppressed the adhesion of the ECA-109 cells, compared with the control group, which occurred in a dose-dependent manner. The adhesion rates in the 10,25 and $50 \mu \mathrm{M}$ of HB-treated groups were $\sim 76.22,32.22$ and $21.34 \%$ respectively, compared with the control group.

The invasive ability of the ECA-109 human esophageal carcinoma cells treated with HB were identified using a Transwell assay. The results revealed that the invasive abilities of the cells treated with 10,25 and $50 \mu \mathrm{M} \mathrm{HB}$ were decreased notably, in a concentration-dependent manner, compared with that of the control group (Fig. 2B). The invasive rates of the 10, $25,50 \mu \mathrm{M}$ HB-treated groups were $\sim 71.25,45.24$ and $21.25 \%$, respectively, compared with control group.

$H B$ suppresses the phosphorylation of PI3K/AKT and the expression of $\beta$-catenin. PI3K/AKT signaling exerts a stimulatory effect in the process of tumor metastasis $(14,15)$. $\beta$-catenin is a scaffold protein, linking the cytoplasmic tail of classical cadherins in the endothelium to the actin cytoskeleton, and its downregulation can give rise to metastasis of esophageal carcinoma (16). In the present study, the expression levels of $\mathrm{p}-\mathrm{PI} 3 \mathrm{~K}, \mathrm{p}-\mathrm{AKT}$ and $\beta$-catenin were measured using western blot analysis. As shown in Fig. 3A-F, the expression levels of $\mathrm{p}-\mathrm{PI} 3 \mathrm{~K}, \mathrm{p}-\mathrm{AKT}$ and $\beta$-catenin were suppressed significantly in the HB-treated ECA-109 cells, in a dose-dependent manner, compared with the control group.

$H B$ inhibits the expression levels of snail, E-cadherin and vimentin in ECA-109 cells. E-cadherin is a tumor suppressor

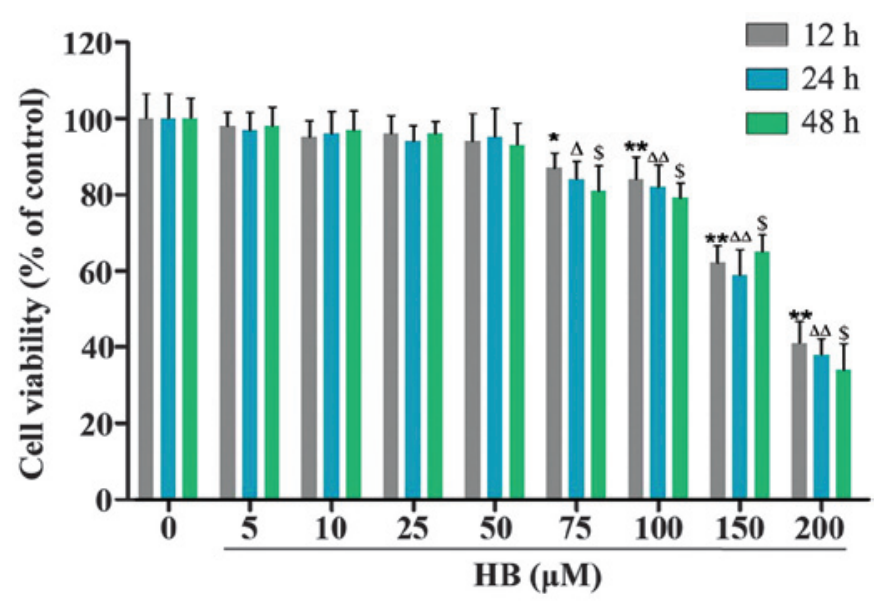

Figure 1. Effect of HB on the proliferation of ECA-109 human esophageal carcinoma cells. The cells were treated with different doses of $\mathrm{HB}(0,5,10$, 25, 50, 100 and $200 \mu \mathrm{M}$ ) for 12, 24 and $48 \mathrm{~h}$, and a Cell Counting Kit 8 assay was performed to determine the proliferation. Data are presented as the mean \pm standard deviation $(\mathrm{n}=3)$. ${ }^{*} \mathrm{P}<0.05$ and ${ }^{* *} \mathrm{P}<0.01$ vs. $0 \mu \mathrm{M}, 12 \mathrm{~h}$; ${ }^{\Delta} \mathrm{P}<0.05$ and ${ }^{\Delta \Delta} \mathrm{P}<0.01$ vs $0 \mu \mathrm{M}, 24 \mathrm{~h} ;{ }^{\$} \mathrm{P}<0.05$ vs $0 \mu \mathrm{M}, 48 \mathrm{~h}$. HB, heterophyllin B.

protein, which is used as a prognostic marker for esophageal cancer $(16,17)$. Vimentin is crucial in carcinoma cell adhesion (18), and is one of intermediate filament proteins which, combined with microtubule and actin microfilaments, constitute the body of the cytoskeleton $(19,20)$. These proteins are dependable indicators in assessing cell adhesion. Snail is recognized as the upstream transcription factor regulating the expression of E-cadherin $(21,22)$. RT-qPCR and western blot analyses were used in the present study to detect the expression levels of these two proteins. The results demonstrated that, compares with the control, the mRNA expression of E-cadherin was increased in a dose-dependent manner following HB treatment. The mRNA expression levels of vimentin and snail were markedly decreased in the HB-treated ECA-109 cells, in a concentration-dependent manner, compared with the control group (Fig. 4A-C). In the results of the western blot analysis, marked decreases were observed in the expression levels of snail and vimentin, and a notable increase was observed in the protein expression of E-cadherin (Fig. 4D and E).

$H B$ inhibits the expression levels of MMP-2/9 in ECA-109 cells. MMPs are produced by esophageal carcinoma cells, and increased expression levels are associated with disease progression $(23,24)$. The expression levels of MMP2 and MMP9 correspond with cell invasive ability (25). To examine the possible anti-invasive mechanism of $\mathrm{HB}$, the activity and expression levels of MMP-2 and MMP-9 in ECA-109 cells exposed to different concentrations of HB were examined. RT-qPCR and western blot analyses were performed to assess the activities of MMP-2 and MMP-9 in the cells treated with various concentrations of HB. As shown in Fig. 5A-C, HB exerted an inhibitory effect on the mRNA expression and protein levels of MMP-2 and MMP-9, in a concentration-dependent manner, compared with the control group.

$H B$ inhibits the adhesion and invasion of ECA-109 esophageal carcinoma cells targeting PI3K/AKT/ $\beta$-catenin. The 
A

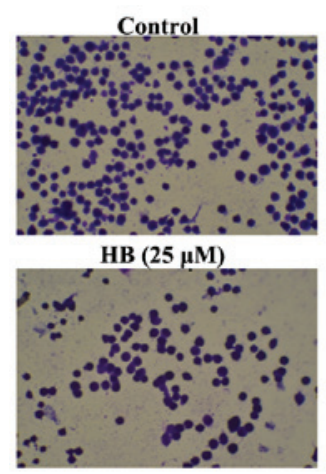

C

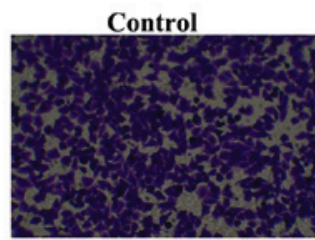

$\mathrm{HB}(25 \mu \mathrm{M})$

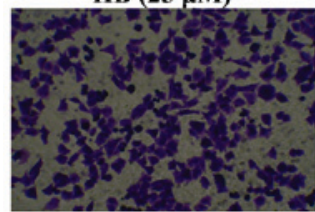

$\mathrm{HB}(10 \mu \mathrm{M})$

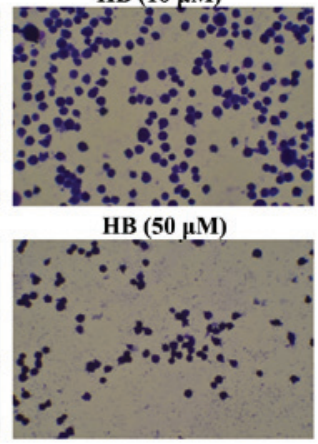

HB $(10 \mu M)$

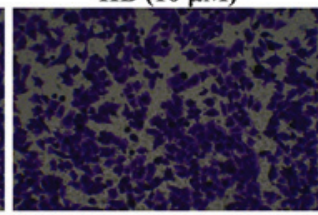

$\mathrm{HB}(50 \mu \mathrm{M})$

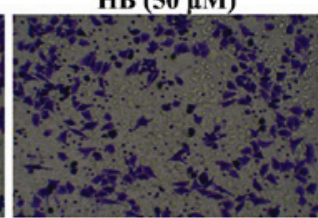

B

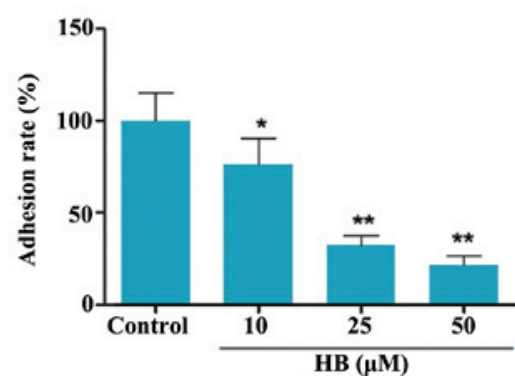

D

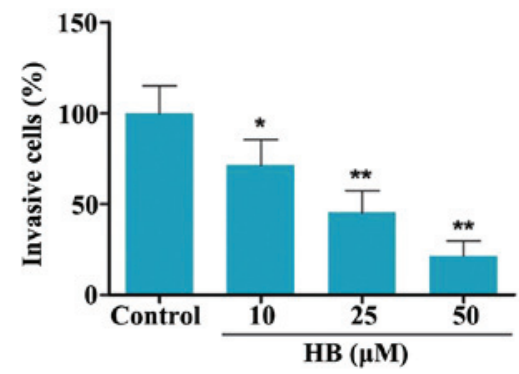

Figure 2. Effect of HB on the adhesion and invasion of ECA-109 human esophageal carcinoma cells. (A and B) Cells were treated with different concentrations of $\mathrm{HB}(0,10,25$ and $50 \mu \mathrm{M})$ for $24 \mathrm{~h}$, and cell adhesion was measured using Giemsa staining. (C and D) Cells were treated with different concentrations of HB $(0,10,25$ and $50 \mu \mathrm{M})$ for $24 \mathrm{~h}$, and cell invasion was determined using a Transwell assay. Data are presented as the mean \pm standard deviation $(\mathrm{n}=3),{ }^{*} \mathrm{P}<0.05$ and ${ }^{* *} \mathrm{P}<0.01$ vs. control. Magnification, $\mathrm{x} 200$. HB, heterophyllin B.

A

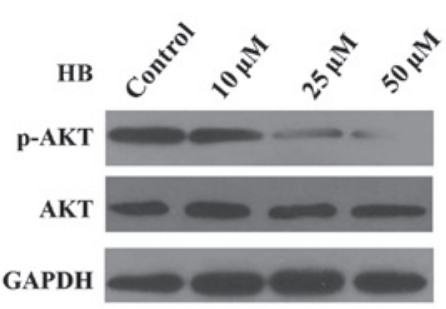

D

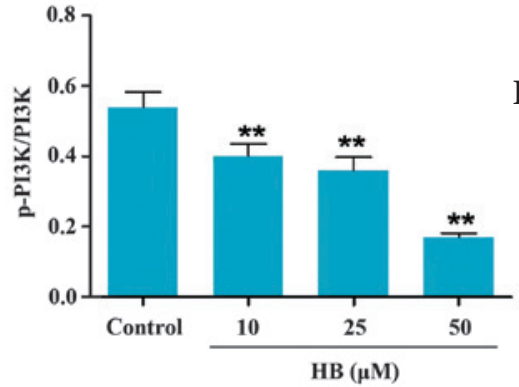

B

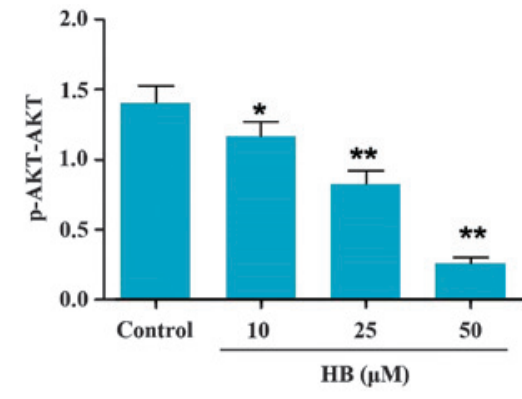

$\mathbf{E}$

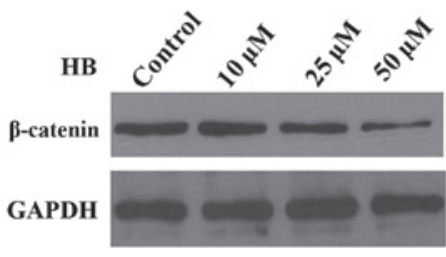

C

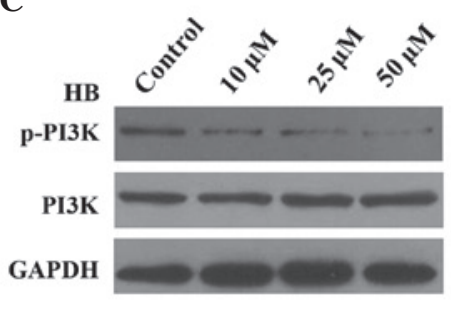

F

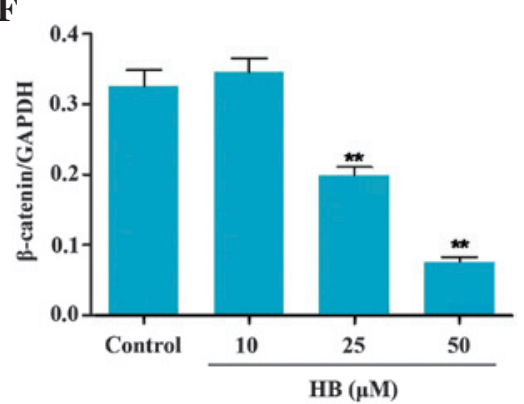

Figure 3. Effect of HB on the phosphorylation of ATK and PI3K in ECA-109 cells. (A and B) Cells were treated with HB $(0,10,25$ and $50 \mu \mathrm{M})$ for $6 \mathrm{~h}$ and lysed for western blot analysis using antibodies against the indicated AKT and p-AKT proteins. (C and D) Cells were treated with $\mathrm{HB}(0,10,25$ and $50 \mu \mathrm{M})$ for $6 \mathrm{~h}$ and lysed for western blot analysis using antibodies against the indicated PI3K and p-PI3K proteins and (E and F) $\beta$-catenin. GAPDH was detected as a control of sample loading. Data are presented as the mean \pm standard deviation $(\mathrm{n}=6)$. " $\mathrm{P}<0.05$ and ${ }^{* * *} \mathrm{P}<0.01$. HB, heterophyllin $\mathrm{B}$; PI3K, phosphoinositide 3-kinase; p-phosphorylated.

present study further investigated the effects of $\mathrm{HB}$ on the adhesion and invasion of ECA-109 cells treated with PI3K activating peptide (740Y-P). Treatment with 740Y-P for
$3 \mathrm{~h}$ markedly increased cell adhesion and invasion (Fig. 6) by $164.08 \pm 9.36$ and $121.12 \pm 9.63 \%$ respectively, which were higher than those of the control group $(100 \pm 7.34$ and 
A

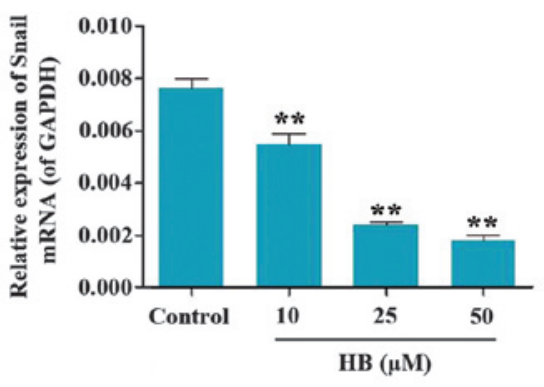

D

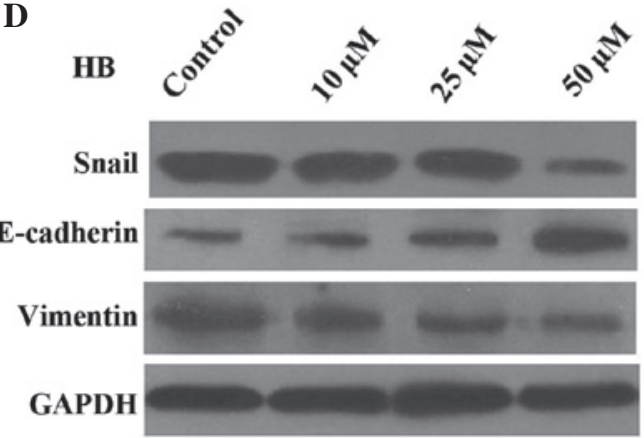

C

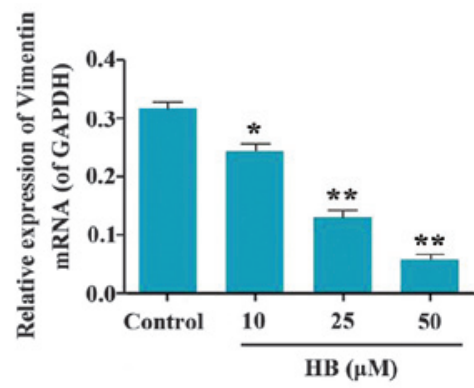

$\mathbf{E}$

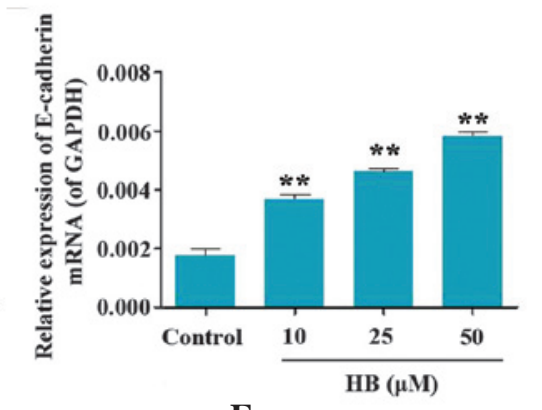

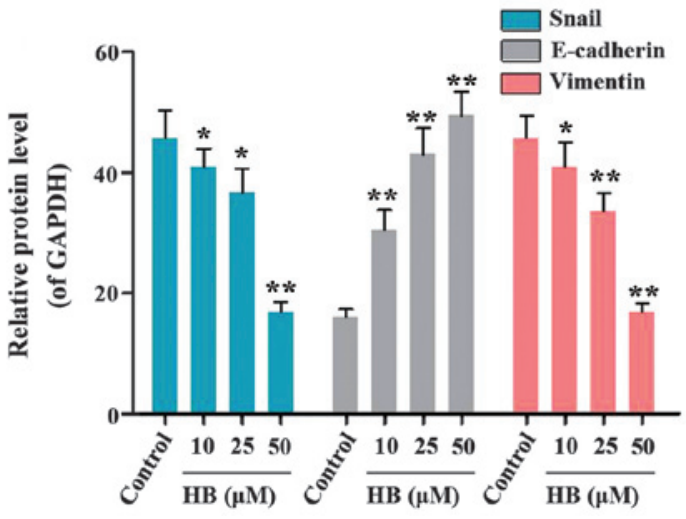

Figure 4. Effect of HB on the expression levels of snail, E-cadherin and vimentin. (A-C) Cells were treated with different doses of $\mathrm{HB}(0,10,25$ and $50 \mu \mathrm{M})$ for $12 \mathrm{~h}$ and reverse transcription-quantitative polymerase chain reaction was performed for mRNA detection. (D and E) Cells were treated with different doses of $\mathrm{HB}(0,10,25$ and $50 \mu \mathrm{M})$ for $24 \mathrm{~h}$ and lysed for western blot analysis using antibodies against the snail, E-cadherin and vimentin proteins. GAPDH was also detected as a control of sample loading. Data are presented as the mean \pm standard deviation $(n=6)$. " $\mathrm{P}<0.05$ and ${ }^{* *} \mathrm{P}<0.01$ vs. control. HB, heterophyllin $\mathrm{B}$.

A

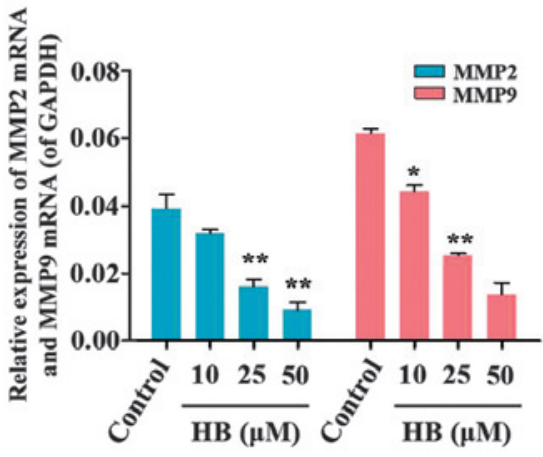

B

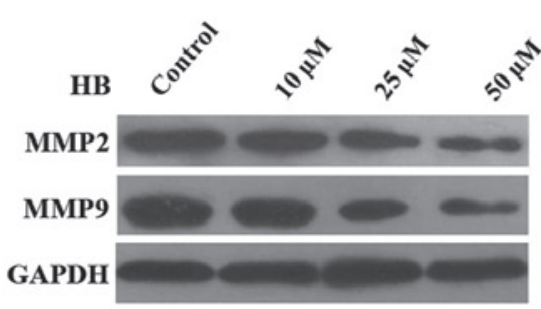

C

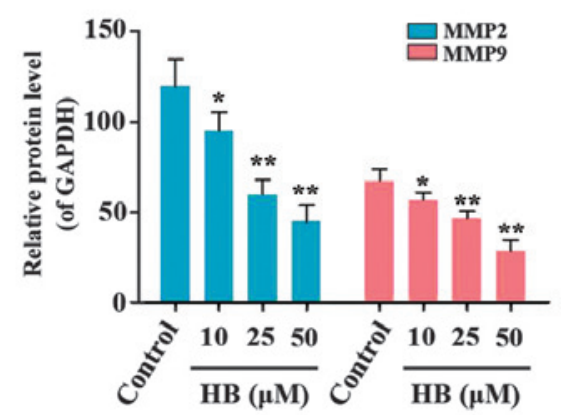

Figure 5. Effect of HB on expression levels of MMP-2 and MMP-9. (A) Cells were treated with HB (0,10,25 and $50 \mu \mathrm{M})$ for $12 \mathrm{~h}$ and reverse trancsription-quantitative polymerase chain reaction was performed to detect mRNA expression levels of MMP 2 and MMP 9. (B and C) Cells were treated with HB $(0,10,25$ and $50 \mu \mathrm{M}$ ) for $24 \mathrm{~h}$ and lysed for western blot analysis using antibodies against MMP 2 and MMP 9 proteins. GAPDH was also detected as a control of sample loading. Data are presented as the mean \pm standard deviation $(\mathrm{n}=6)$. ${ }^{*} \mathrm{P}<0.05$ and ${ }^{* *} \mathrm{P}<0.01$ vs. control. HB, heterophyllin $\mathrm{B}$; MMP, matrix metalloproteinase.

$100 \pm 8.29 \%$, respectively), suggesting that the PI3K-activating peptide effectively facilitated adhesion and invasion. Following treatment with HB $(25 \mu \mathrm{M})$ alone for $24 \mathrm{~h}$, cell adhesion and invasion were $17.07 \pm 4.23$ and $35.21 \pm 7.55 \%$ of the control group, respectively (Fig. 6). In addition, following pretreatment with 740Y-P for $3 \mathrm{~h}$, cell adhesion and invasion decreased significantly with $\mathrm{HB}+740 \mathrm{Y}-\mathrm{P}$ by $29.26 \pm 2.30 \%$ and $62.50 \pm 7.09 \%$, respectively (Fig. 6).

$H B$ inhibits the expression levels of adhesion- and invasion-associated proteins targeting PI3K/AKT/ $\beta$-catenin. Cells were pretreated with 740Y-P for $6 \mathrm{~h}$ and then cultured for $3 \mathrm{~h}$.
Compared with the control group, the levels of p-AKT/AKT and $\beta$-catenin were increased (Fig.7Aa-c). The protein levels of snail, vimentin, MMP2 and MMP9 were upregulated and the expression of E-cadherin was decreased (Fig. 7Ba-c). The cells were then treated with HB $(25 \mu \mathrm{M})$ for $6 \mathrm{~h}$, following which the levels of p-AKT/AKT and $\beta$-catenin decreased markedly (Fig. 7A-C). Following 24 h HB treatment, significant decreases were observed in the expression levels of snail, vimentin, MMP2 and MMP9, and the expression of E-cadherin was upregulated, compared with the control group (Fig. 7D-F). These results suggested that HB adjusted the abnormal levels of protein expression, which caused by 740Y-P. 
A

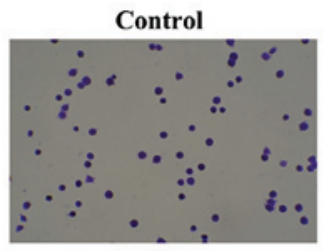

740Y-P

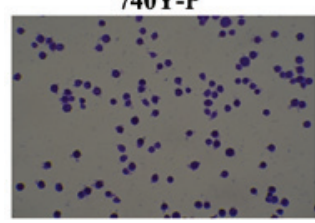

C

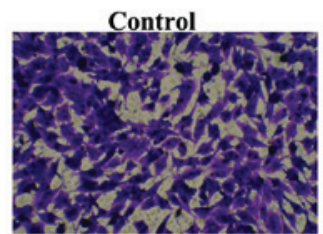

740Y-P)

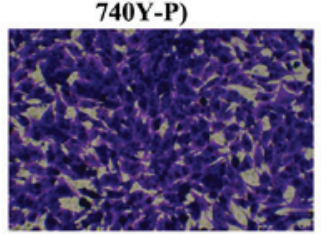

HB $(25 \mu \mathrm{M})$

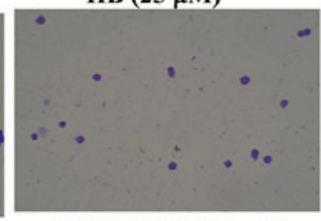

$740 \mathrm{Y}-\mathrm{P}+\mathrm{HB}(25 \mu \mathrm{M})$

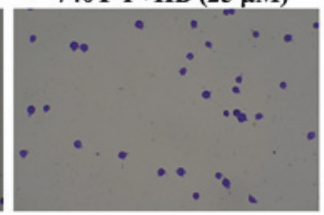

HB (25 $\mu$ M)

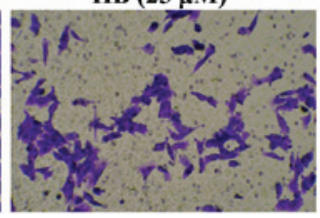

740Y-P+HB $(25 \mu \mathrm{M})$

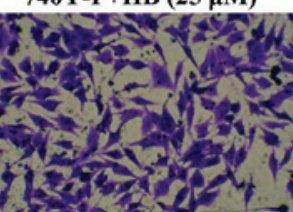

B

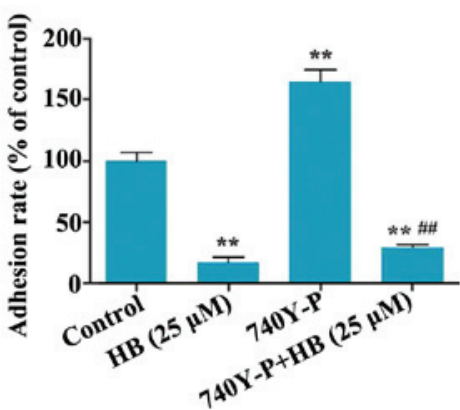

D

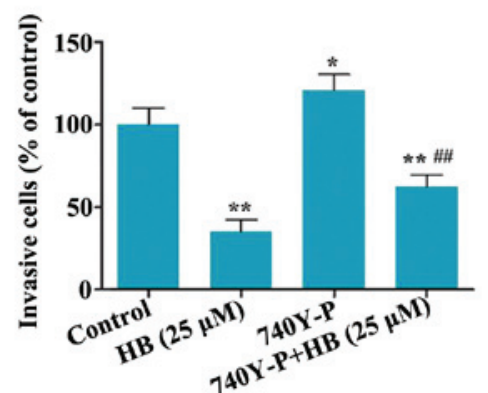

Figure 6. Effect of HB on the adhesion and invasion of ECA-109 cells pretreated with PI3K-activating peptide. (A and B) Cells were pretreated with 740Y-P for $3 \mathrm{~h}$, then treated with $\mathrm{HB}(25 \mu \mathrm{M})$ for $24 \mathrm{~h}$. Cell adhesion was measured using Giemsa staining. (C and D) Cell invasion was determined using a Transwell assay. Data are presented as the mean \pm standard deviation $(\mathrm{n}=3)$. ${ }^{*} \mathrm{P}<0.05$ and ${ }^{* *} \mathrm{P}<0.01$, vs. control; ${ }^{\# \#} \mathrm{P}<0.01$, vs. 740Y-P. Magnification, $\mathrm{x} 200$. HB, heterophyllin B; PI3K, phosphoinositide 3-kinase.

A
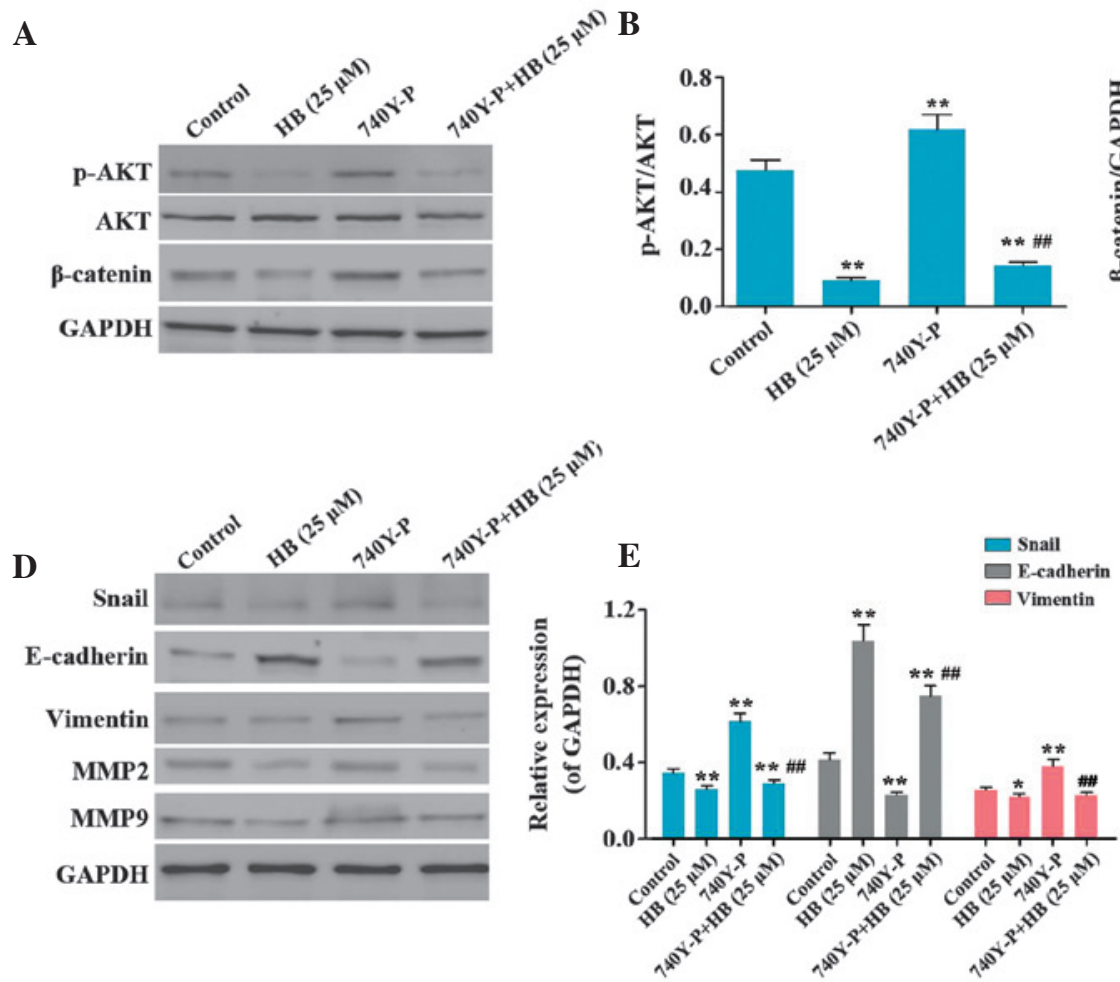

C

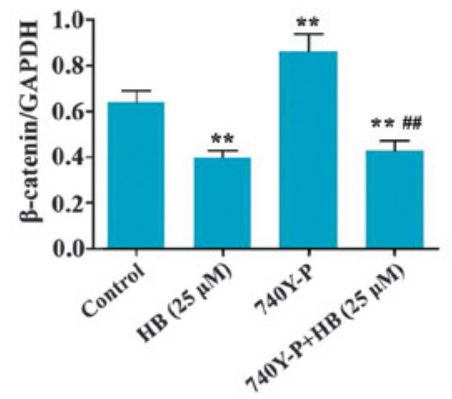

\section{$\mathbf{F}$}

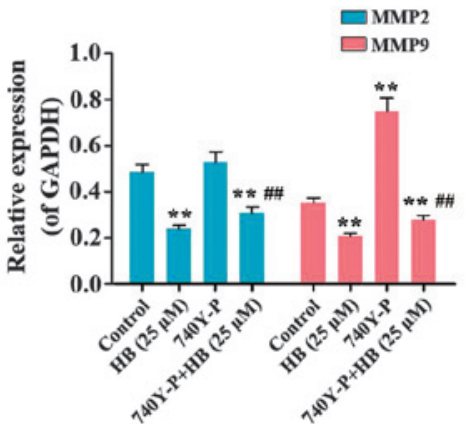

Figure 7. Effect of HB on the protein levels in ECA-109 cells pretreated with PI3K-activating peptide. (A-C) Cells were pretreated with $740 \mathrm{Y}-\mathrm{P}$ for $3 \mathrm{~h}$, then treated with $\mathrm{HB}(25 \mu \mathrm{M})$ for $6 \mathrm{~h}$. Expression levels of p-AKT, AKT and $\beta$-catenin were determined using western blot analysis. (D-F) Cells were pretreated with 740Y-P for $3 \mathrm{~h}$, then treated with HB $(25 \mu \mathrm{M})$ for $24 \mathrm{~h}$. The expression levels of snail, E-cadherin, vimentin, MMP2 and MMP9 were determined using western blot analysis. GAPDH was also detected as a control of sample loading. Data are presented as the mean \pm standard deviation ( $\mathrm{n}=3$ ). ${ }^{*} \mathrm{P}<0.05$ and ${ }^{* *} \mathrm{P}<0.01$, vs. control; ${ }^{\# \#} \mathrm{P}<0.01$, vs. 740Y-P. HB, heterophyllin B; PI3K, phosphoinositide 3-kinase; MMP, matrix metalloproteinase; p-phosphorylated. 


\section{Discussion}

Esophageal carcinoma, characterized by a low cure rate is considered a serious disease and a significant threat to human health. Traditional Chinese medicine, surgery, radiotherapy and chemotherapy in the treatment of esophageal cancer can effectively reduce the toxicity and strengthen immune function. In addition, the combination of Chinese and Western medicines assist in preventing the recurrence and metastasis, and improve quality of life and survival rates (1-3). Therefore, identifying favorable products from Chinese medicinal herbs for carcinoma therapy is of importance.

Cyclic peptides, present extensively in medicinal plants usually possess novel structures, diverse biological activities and unique mechanisms of action, and are crucial in natural products $(26,27)$. Therefore, the investigation of cyclic peptides is receiving increasing attention from scientists. $\mathrm{HB}$ is an active cyclic peptide isolated from Pseudostellaria heterophylla (8). The present study focussed on the effect of HB on the adhesion and invasion of ECA-109 human esophageal cancer cells.

Adhesion and invasion are essential processes in the metastasis of esophageal cancer. The presence of metastasis is the predominant cause of low cure rates in millions of patients diagnosed with cancer (28-30). In the present study, HB was demonstrated to inhibit esophageal cancer cell proliferation, adhesion and invasion. It also provided evidence that the mechanism underlying the above effects was associated with inhibition in the expression of snail, vimentin and MMP-2/9, which are regulated by the PI3K/AKT/ $\beta$-catenin signaling pathway (31). These novel findings assist in further investigating the effects HB on esophageal cancer metastasis.

The metastasis of esophageal cancer cells is a complex multistep process, involving cell adhesion, invasion and migration (32). Therefore, interruption of one or more of these processes is considered a serviceable strategy for targeting in treatment. In the present study, the results indicated that HB induced marked inhibition of adhesion and invasion in the ECA-109 human esophageal carcinoma cell line in a dose-dependent manner. Cellular functions are regulated by multiple signal pathways, and the PI3K/AKT pathway is crucial in cell survival, proliferation, invasion and migration (33). $\beta$-catenin is a scaffold protein, linking the cytoplasmic tail of classical cadherins in the endothelium via $\beta$-catenin to the actin cytoskeleton (34). Numerous experimental studies have indicated that $\beta$-catenin is a key regulator of esophageal carcinoma metastasis (16). The present study also found that HB effectively inhibited the increased adhesion and invasion caused by the PI3K activating peptide. These results demonstrated that this pathway was inhibited in the ECA-109 cells treated with $\mathrm{HB}$, which indicated the anti-adhesion and anti-invasive activities of $\mathrm{HB}$.

Vimentin is the major intermediate filament (IF) protein of mesenchymal cells, and is important in cell-cell adhesion through their association with hemidesmosomes and desmosomes (18). Reduced expression levels of E-cadherin have been reported in numerous types of carcinoma originating from epithelial cells, including gastric, breast, pancreatic and hepatic cancer, and its downregulation is frequently associated with metastasis and invasiveness $(35,36)$. The E-cadherin gene is frequently downregulated by specific transcriptional repressors, including zinc finger proteins of the snail family, snail and slug $(37,38)$. Vimentin, snail and E-cadherin are regulated by diverse signaling pathways, and the PI3K/ AKT $/ \beta$-catenin pathway is reported to regulate their expression (39-41). Accordingly, the expression levels of E-cadherin, snail and vimentin in the present study were regulated in the cells treated with $\mathrm{HB}$.

The initial step of tumor cell invasion begins with the breakdown of the cytomembrane, a process that is dependent on type IV collagen-degrading enzymes, predominantly MMP-2 and MMP-9 $(42,43)$. The expression levels of MMPs, particularly MMP-2 and MMP-9, have been associated with increased chances of metastasis in several types of human carcinoma, including esophageal cancer $(44,45)$. RT-qPCR and western blot analyses were used in the present study to investigate the expression levels of MMP-2 and MMP-9 in the ECA-109 cells following $\mathrm{HB}$ treatment $(24 \mathrm{~h})$. The results demonstrated that HB effectively suppressed the expression levels of MMP-2 and MMP-9, including the abnormal level of expression induced by 740Y-P. Downregulation of the expression levels of MMP-2 and MMP-9 are mediated by multiple signaling cascades, particularly by the PI3K/AKT pathway (46). The suppression of the PI3K/AKT/ $\beta$-catenin signaling by $\mathrm{HB}$ may have led to the reductions in MMP-2 and MMP-9 (47).

In conclusion, the present study demonstrated that $\mathrm{HB}$ inhibited the adhesive and invasive properties of the ECA-109 cells by suppressing the activation and expression levels of E-cadherin, vimentin, snail, MMP-2 and MMP-9, which are important factors in esophageal cancer cells. $\mathrm{PI} 3 \mathrm{~K} / \mathrm{AKT} / \beta$-catenin signaling in the ECA-109 cells contributed to the underlying mechanism of the invasive potential of HB. These results may be relevant for esophageal carcinoma therapy.

\section{References}

1. Zhang L, Sun J,Zhang JQ, Yang M, Bai G and Ma XL: Expression and significance of molecular biomarkers in esophageal carcinoma in different nationalities patients in Xinjiang. Genet Mol Res 13: 5413-5425, 2014.

2. Shin D, Protano MA, Polydorides AD, Dawsey SM, Pierce MC, Kim MK, Schwarz RA, Quang T, Parikh N, Bhutani MS, et al: Quantitative analysis of high-resolution microendoscopic images for diagnosis of esophageal squamous cell carcinoma. Clin Gastroenterol Hepatol 13: 272-279. e2, 2015.

3. Dey B, Raphael V, Khonglah Y and Lynrah KG: Immunohistochemical analysis of P53 and PRB in esophageal squamous cell carcinoma. J Clin Diagn Res 8: FC01-FC03, 2014.

4. Daly JM, Fry WA, Little AG, Winchester DP, McKee RF, Stewart AK and Fremgen AM: Esophageal cancer: Results of an American College of Surgeons patient care evaluation study. J Am Coll Surg 190: 562-573, 2000.

5. Schneider T, Müller A, Miess H and Gross H: Cyclic lipopeptides as antibacterial agents-potent antibiotic activity mediated by intriguing mode of actions. Int J Med Microbiol 304: 37-43, 2014.

6. Farace G, Fernandez O, Jacquens L, Coutte F, Krier F, Jacques P, Clément C, Barka EA, Jacquard C and Dorey S: Cyclic lipopeptides from Bacillus subtilis activate distinct patterns of defence responses in grapevine. Mol Plant Pathol 16: 177-187, 2014.

7. Zhang DJ, Liu RF, Li YG, Tao LM and Tian L: Two new antifungal cyclic lipopeptides from Bacillus marinus B-9987. Chem Pharm Bull (Tokyo) 58: 1630-1634, 2010.

8. Zhao WO, Pang L, Dong N and Yang S: LC-ESI-MS/MS analysis and pharmacokinetics of heterophyllin B, a cyclic octapeptide from Pseudostellaria heterophylla in rat plasma. Biomed Chromatogr, May12, 2015 (epub ahead of print). 
9. Livak KJ and Schmittgen TD. Analysis of relative gene expression data using real-time quantitative PCR and the 2[-Delta DeltaC(T)] method. Methods 25:402-408, 2001.

10. Ye ZY, Deng H, Jian MX, Zheng S and Tian HQ: Anther development and sperm isolation of Pseudostellaria heterophylla (Miq.). Fen Zi Xi Bao Sheng Wu Xue Bao 40: 428-436, 2007 (In Chinese)

11. Wang HX and Ng TB: Concurrent isolation of a Kunitz-type trypsin inhibitor with antifungal activity and a novel lectin from Pseudostellaria heterophylla roots. Biochem Biophys Res Commun 342: 349-353, 2006.

12. Xu M, Qian G, Xie F, Shi C, Yan L, Yu L, Zheng T, Wei L and Yang J: Expression of epithelial cell adhesion molecule associated with elevated ductular reactions in hepatocellar carcinoma. Clin Res Hepatol Gastroenterol 38: 699-705, 2014.

13. Yamada S, Utsunomiya T, Morine Y, Imura S, Ikemoto T, Arakawa Y, Kanamoto M, Iwahashi S, Saito Y, Takasu C, et al: Expressions of hypoxia-inducible factor- 1 and epithelial cell adhesion molecule are linked with aggressive local recurrence of hepatocellular carcinoma after radiofrequency ablation therapy. Ann Surg Oncol 21 (Suppl 3): S436-S442, 2014.

14. Sabine VS, Crozier C, Brookes CL, Drake C, Piper T, van de Velde CJ, Hasenburg A, Kieback DG, Markopoulos C, Dirix L, et al: Mutational analysis of PI3K/AKT signaling pathway in tamoxifen exemestane adjuvant multinational pathology study. J Clin Oncol 32: 2951-2958, 2014.

15. Toulany M, Minjgee M, Saki M, Holler M, Meier F, Eicheler W and Rodemann HP: ERK2-dependent reactivation of Akt mediates the limited response of tumor cells with constitutive K-RAS activity to PI3K inhibition. Cancer Biol Ther 15: 317-328, 2014.

16. Yang Y, Yang JJ, Tao H and Jin WS: New perspectives on $\beta$-catenin control of cell fate and proliferation in colon cancer. Food Chem Toxicol 74: 14-19, 2014.

17. Nakagawa Y, Ohira M, Kubo N, Yamashita Y, Sakurai K, Toyokawa T, Tanaka H, Muguruma K, Shibutani M, Yamazoe S, et al: Tumor budding and E-cadherin expression are useful predictors of nodal involvement in T1 esophageal squamous cell carcinoma. Anticancer Res 33: 5023-5029, 2013.

18. Ivaska J, Pallari HM, Nevo J and Eriksson JE: Novel functions of vimentin in cell adhesion, migration and signaling. Exp Cell Res 313: 2050-2062, 2007.

19. Bartoloni E, Alunno A, Bistoni O, Bizzaro N, Migliorini P, Morozzi G, Doria A, Mathieu A, Lotzniker M, Allegri F, et al: Diagnostic value of anti-mutated citrullinated vimentin in comparison to anti-cyclic citrullinated peptide and anti-viral citrullinated peptide 2 antibodies in rheumatoid arthritis: An Italian multicentric study and review of the literature. Autoimmun Rev 11: 815-820, 2012.

20. Luime JJ, Colin EM, Hazes JM and Lubberts E: Does anti-mutated citrullinated vimentin have additional value as a serological marker in the diagnostic and prognostic investigation of patients with rheumatoid arthritis? A systematic review. Ann Rheum Dis 69: 337-344, 2010

21. Nieto MA: The snail superfamily of zinc-finger transcription factors. Nat Rev Mol Cell Biol 3: 155-166, 2002.

22. Zhou BP, Deng J, Xia W, Xu J, Li YM, Gunduz M and Hung MC: Dual regulation of Snail by GSK-3beta-mediated phosphorylation in control of epithelial-mesenchymal transition. Nat Cell Biol 6: 931-940, 2004

23. Zhang DH, Zhang LY, Liu DJ, Yang F and Zhao JZ: Expression and significance of MMP-9 and MDM2 in the oncogenesis of lung cancer in rats. Asian Pac J Trop Med 7: 585-588, 2014.

24. Sun S, Henriksen K, Karsdal MA, Armbrecht G, Belavý DL, Felsenberg D, Rittweger J, Wang Y, Zheng Q and Nedergaard AF: Measurement of a MMP-2 degraded Titin fragment in serum reflects changes in muscle turnover induced by atrophy. Exp Gerontol 58: 83-89, 2014

25. Chen L, Zhou Q, Xu B, Liu J, Shi L, Zhu D, Wu C and Jiang J: MT2-MMP expression associates with tumor progression and angiogenesis in human lung cancer. Int J Clin Exp Pathol 7: 3469-3477, 2014

26. Barber CJ, Pujara PT, Reed DW, Chiwocha S, Zhang H and Covello PS: The two-step biosynthesis of cyclic peptides from linear precursors in a member of the plant family Caryophyllaceae involves cyclization by a serine protease-like enzyme. J Biol Chem 288: 12500-12510, 2013.
27. Monroc S, Badosa E, Feliu L, Planas M, Montesinos E and Bardaji E: De novo designed cyclic cationic peptides as inhibitors of plant pathogenic bacteria. Peptides 27: 2567-2574, 2006.

28. Xu J and Wu CL: Anti-metastasis of celastrol on esophageal cancer cells and its mechanism. Sheng Li Xue Bao 67: 341-347, 2015.

29. Perlikos F, Harrington KJ and Syrigos KN: Key molecular mechanisms in lung cancer invasion and metastasis: A comprehensive review. Crit Rev Oncol Hematol 87: 1-11, 2013.

30. Gimona $\mathrm{M}$ and Buccione R: Adhesions that mediate invasion. Int J Biochem Cell Biol 38: 1875-1892, 2006.

31. Zhang B, Yin C, Li H, Shi L, Liu N, Sun Y, Lu S, Liu Y, Sun L, Li X, et al: Nirl promotes invasion of breast cancer cells by binding to chemokine (C-C motif) ligand 18 through the PI3K/Akt/ GSK3 $3 /$ Snail signalling pathway. Eur J Cancer 49: 3900-3913, 2013.

32. Xu M, Huang H, Xiong Y, Peng B, Zhou Z, Wang D and Yang X: Combined chemotherapy plus endostar with sequential stereotactic radiotherapy as salvage treatment for recurrent esophageal cancer with severe dyspnea: A case report and review of the literature. Oncol Lett 8: 291-294, 2014.

33. Polivka J Jr and Janku F: Molecular targets for cancer therapy in the PI3K/AKT/mTOR pathway. Pharmacol Ther 142: 164-175, 2014.

34. Yang LH, Xu HT, Han Y, Li QC, Liu Y, Zhao Y, Yang ZQ, Dong QZ, Miao Y, Dai SD et al: Axin downregulates TCF-4 transcription via $\beta$-catenin, but not $\mathrm{p} 53$, and inhibits the proliferation and invasion of lung cancer cells. Mol Cancer 9: 25, 2010.

35. Colas E, Pedrola N, Devis L, Ertekin T, Campoy I, Martínez E, Llauradó M, Rigau M, Olivan M, Garcia M, et al: The EMT signaling pathways in endometrial carcinoma. Clin Transl Oncol 14: 715-720, 2012

36. Gao D, Vahdat LT, Wong S, Chang JC and Mittal V: Microenvironmental regulation of epithelial-mesenchymal transitions in cancer. Cancer Res 72: 4883-4889, 2012.

37. Cai J: Roles of transcriptional factor Snail and adhesion factor E-cadherin in clear cell renal cell carcinoma. Exp Ther Med 6: 1489-1493, 2013.

38. Cheng JC, Chang HM and Leung PC: Transforming growth factor- $\beta 1$ inhibits trophoblast cell invasion by inducing Snail-mediated down-regulation of vascular endothelial-cadherin protein. J Biol Chem 288: 33181-33192, 2013.

39. Hao L, Ha JR, Kuzel P, Garcia E and Persad S: Cadherin switch from $\mathrm{E}$ - to $\mathrm{N}$-cadherin in melanoma progression is regulated by the PI3K/PTEN pathway through Twist and Snail. Br J Dermatol 166: 1184-1197, 2012.

40. Zhu Y, Xu L, Zhang J, Xu W, Liu Y, Yin H, Lv T, An H, Liu L, $\mathrm{He} \mathrm{H}$, et al: Klotho suppresses tumor progression via inhibiting $\mathrm{PI} 3 \mathrm{~K} / \mathrm{Akt} / \mathrm{GSK} 3 \beta /$ Snail signaling in renal cell carcinoma. Cancer Sci 104: 663-671, 2013.

41. Jasaitis A, Estevez M, Heysch J, Ladoux B and Dufour S: E-cadherin-dependent stimulation of traction force at focal adhesions via the Src and PI3K signaling pathways. Biophys J 103: 175-184, 2012.

42. Radenkovic S, Konjevic G, Jurisic V, Karadzic K, Nikitovic M and Gopcevic K: Values of MMP-2 and MMP-9 in tumor tissue of basal-like breast cancer patients. Cell Biochem Biophys 68: 143-152, 2014.

43. Chen L, Zhou Q, Xu B, Liu J, Shi L, Zhu D, Wu C and Jiang J: MT2-MMP expression associates with tumor progression and angiogenesis in human lung cancer. Int J Clin Exp Pathol 7: 3469-3477, 2014

44. Samantaray S, Sharma R, Chattopadhyaya TK, Gupta SD and Ralhan R: Increased expression of MMP-2 and MMP-9 in esophageal squamous cell carcinoma. J Cancer Res Clin Oncol 130: 37-44, 2004

45. Li Y, Ma J, Guo Q, Duan F, Tang F, Zheng P, Zhao Z and Lu G: Overexpression of MMP-2 and MMP-9 in esophageal squamous cell carcinoma. Dis Esophagus 22: 664-667, 2009.

46. Kang MH, Oh SC, Lee HJ, Kang HN, Kim JL, Kim JS and Yoo YA: Metastatic function of BMP-2 in gastric cancer cells: The role of PI3K/AKT, MAPK, the NF- $\kappa$ B pathway and MMP-9 expression. Exp Cell Res 317: 1746-1762, 2011.

47. Yang CQ, Li W, Li SQ, Li J, Li YW, Kong SX, Liu RM, Wang SM and Lv WM: MCP-1 stimulates MMP-9 expression via ERK $1 / 2$ and p38 MAPK signaling pathways in human aortic smooth muscle cells. Cell Physiol Biochem 34: 266-276, 2014. 